\title{
JD10
}

\section{Low Luminosity Stars}

\author{
Chairperson and Editor: J. J. Binney
}

